\title{
The Emergency Use Authorization of Pharmaceuticals: History and Utility During the COVID-19 Pandemic
}

\author{
Allan $\operatorname{Tran}^{1} \cdot$ Theodore J. Witek Jr ${ }^{1,2}$ (1) \\ Accepted: 4 August 2021 / Published online: 28 August 2021 \\ (c) The Author(s), under exclusive licence to Springer Nature Switzerland AG 2021
}

\begin{abstract}
The Emergency Use Authorization (EUA) originated in 2004 because of the need for emergency medical countermeasures (MCMs) against potential bioterrorist attacks. The EUA also proved useful in dealing with subsequent pandemics and has emerged as a critical regulatory pathway for therapeutics and vaccines throughout the Coronavirus Disease 2019 (COVID19) pandemic. With the EUA process in the USA, we witnessed emergency authorizations, their expansions, as well as withdrawal of previously authorized products, which exemplifies the dynamic nature of scientific review of EUA products. EUAs proved vital for the first group of COVID-19 vaccines, including the temporary pause of one vaccine while emergency safety issues were evaluated. Although this review on the EUA is primarily focused on the USA, distinctions were made with other jurisdictions such as Europe and Canada with respect to the emergency authorizations of the vaccines. Finally, we discuss some important differences following EUA and formal new drug/vaccine application (NDA/BLA) approvals.
\end{abstract}

\section{Key Points}

The Emergency Use Authorization (EUA) acted as a critical regulatory pathway for therapeutics and vaccines throughout the Coronavirus Disease 2019 (COVID-19) pandemic.

The EUA process demonstrates the dynamic nature of scientific review practices as characterized by emergency authorizations, expansion of the authorizations, and withdrawal of previously authorized products.

EUAs were of critical utility in countering the pandemic and proved a remarkable regulatory framework for a monumental pharmaceutical achievement.

Theodore J. Witek Jr

Ted.Witek@utoronto.ca

1 Institute of Health Policy, Management, and Evaluation, University of Toronto, 155 College Street, Suite 425, Toronto M5T 3M6, Canada

2 Dalla Lana School of Public Health, University of Toronto, Toronto, Canada

\section{Introduction}

Development of therapies and preventative vaccines to attenuate the often-devastating impact of the global COVID19 pandemic have been at the daily forefront of both lay press and medical literature. While the basic public health hygienic measures were the foundation of efforts to ease the spread of infection and its burden, there was also great attention to innovative developments in pharmaceutical medicine.

The pharmaceutical focus during the pandemic was on developing vaccines to protect individual patients and to foster herd immunity and therapies to treat the severe manifestations of disease. With respect to the latter, these developments included both novel therapeutics and, more often, the repurposing of drugs with known safety and efficacy in other indications (e.g., malaria) based on a working hypothesis of potential benefit against COVID-19. In both cases, the Emergency Use Authorization (EUA) served as a regulatory vehicle to allow patient use prior to formal New Drug Application (NDA) submissions. In the first year of the pandemic, we witnessed many approvals of EUAs; but also, amendments and withdrawals as the quickly evolving science drove decision making.

We provide a historical summary of the EUA, including its conception and its application during the first year of the pandemic. We then describe how the EUA program operated to provide safe and effective emergency relief from 
a devastating pandemic with prescription therapeutics and the early availability of vaccines. While diagnostics were the most common medical product that received an EUA from the FDA, we focus exclusively on the use of EUAs for therapeutic interventions aimed at counteracting or preventing COVID-19 infections.

\section{The Purpose and Brief History of the EUA}

\subsection{Bioterrorism Threats Prompt EUA}

After the 2001 anthrax bioterrorist attacks, the Project BioShield Act was enacted in 2004 to accelerate and bolster national security against potential bioterrorist attacks [1]. This legislation established the EUA under Section 564 of the Federal Food, Drug, and Cosmetic Act (FD\&C Act), which permitted the emergency use of unapproved countermeasures against chemical, biological, radiological, or nuclear (CBRN) agent(s), among other authorities, when there are no adequate, approved, and available alternatives [2]. To enhance the flexibility of authorizations made under additional emergency circumstances, Section 564 of the $F D \& C$ Act was further amended by the Pandemic and AllHazards Preparedness Reauthorization Act of 2013 (PAHPRA), the 21 st Century Cures Act of 2016, and Public Law 115-92 of 2017 [2].

The purpose of an EUA is to allow for the use of unapproved medical countermeasures (MCMs) to diagnose, treat, or prevent serious or life-threatening disease or condition in response to a public health, military, and domestic emergency [3]. If the determinations needed to support an EUA declaration in the USA is met, this will enable the Secretary of Homeland Security, Secretary of Defense, Secretary of Department of Health and Human Services (HHS) to declare that circumstances exist to support an authorization [3]. Given that a MCM is considered for EUA for treatment of serious or life-threatening consequences, the FDA will evaluate the evidence of potential effectiveness of the MCM, i.e., whether it may be effective, as well as the associated risk-benefit profile, allowing that there are no adequate, approved, and available alternative options [3]. There were several public statements and media broadcasts that brought a particular drug or agent into the spotlight, which have ultimately turned our attention to the FDA, and to its decisionmaking process that has led to an EUA issuance. Since the inception of the EUA, the first authorization for a vaccine was for the Anthrax Vaccine Adsorbed (AVA) used by the Armed Forced [4] (Table 1).

\subsection{HIV Infection and Expanded Access}

The concept behind the EUA dates back to the decade after the first reported cases of human immunodeficiency virus and acquired immunodeficiency syndrome (HIV/AIDS) in 1981 [5]. Because of the urgent need for additional treatments, the United States Public Health Service (USPHS) created a "parallel track" expanded access program for an investigational drug known as dideoxyinosine (ddI) for AIDS patients with no other alternatives [5]. Notably, this pathway allowed eligible AIDS patients to access ddI while clinical trials of the drug were still ongoing. The fundamental principles of the parallel track/expanded access program formed the basis of the "accelerated approval (AA)" program, which was launched in 1992 [5]. Through the AA mechanism, the FDA was able to grant faster approval of new drugs that treat serious or life-threatening conditions based on a surrogate endpoint that is "reasonably likely" to predict clinical benefit [6], often well before clinical data supporting that benefit could be available. After granting an AA, confirmatory trials are required to verify its clinical effectiveness and benefit to support the AA [7]. The intentions of the EUA were reflected in the 1981 expanded access of ddI for AIDS patients.

\subsection{EUA in Previous Pandemics}

Apart from the significant role that EUAs played in authorizing the emergency use of treatments for $2009 \mathrm{H} 1 \mathrm{~N} 1$ and COVID-19 vaccines $[4,8]$ (Tables 1,2 ), other medical

Table 1 History of emergency use authorizations granted for vaccines in the USA [4, 8]

\begin{tabular}{lll}
\hline Date of first issuance & Treatment & Authorized use \\
\hline 14-Jan-05 & Anthrax vaccine adsorbed & $\begin{array}{l}\text { For prevention of inhalation of Anthrax by individuals at heightened risk of expo- } \\
\text { sure due to attack with Anthrax } \\
\text { 11-Dec-20 }\end{array}$ \\
& Pfizer-BioNTech COVID-19 vaccine & $\begin{array}{l}\text { For the prevention of COVID-19 for individuals aged } \geq 16 \text { years } \\
\text { (Requested an EUA for the use in adolescents [53] and applied for full FDA } \\
\text { approval [54]. Finally, on August 23, 2021, the FDA approved the vaccine for } \\
\text { individuals 16 years or older [44].) }\end{array}$ \\
18-Dec-20 & $\begin{array}{l}\text { For the prevention of COVID-19 for individuals aged } \geq 18 \text { years } \\
\text { 27-Feb-21 }\end{array}$ & $\begin{array}{l}\text { For the prevention of Coronavirus Disease 2019 (COVID-19) for individuals aged } \\
\geq 18 \text { years }\end{array}$ \\
\hline
\end{tabular}

COVID-19 Coronavirus Disease 2019, EUA emergency use authorization, FDA US Food and Drug Administration 
Table 2 Summary list of EUAs granted for therapeutics in the USA [4]

\begin{tabular}{|c|c|c|}
\hline Date of first issuance & Treatment & Authorized use \\
\hline 22-Jun-10 & $\begin{array}{l}\text { Antivirals: oseltamivir (Tamiflu), zanamivir (Relenza), and } \\
\text { peramivir }\end{array}$ & To treat and prevent $2009 \mathrm{H} 1 \mathrm{~N} 1$ influenza \\
\hline 09-Jul-18 & Pathogen-reduced leukocyte-depleted freeze-dried plasma & $\begin{array}{l}\text { For the treatment of hemorrhage or coagulopathy during } \\
\text { an emergency involving agents of military combat (e.g., } \\
\text { firearms, projectiles, and explosive devices) when plasma } \\
\text { is not available for use or when the use of plasma is not } \\
\text { practical }\end{array}$ \\
\hline 30-Apr-20 & $\begin{array}{l}\text { Fresenius Medical, multiFriltrate PRO System and } \\
\text { multiBic/multiPlus solutions }\end{array}$ & $\begin{array}{l}\text { To provide CRRT to treat patients in an acute care environ- } \\
\text { ment during the COVID-19 pandemic }\end{array}$ \\
\hline 01-May-20 & Remdesivir for certain hospitalized COVID-19 patients & $\begin{array}{l}\text { For the treatment of suspected or laboratory-confirmed } \\
\text { COVID- } 19 \text { in hospitalized pediatric patients weighing } \\
3.5 \mathrm{~kg} \text { to }<40 \mathrm{~kg} \text { or hospitalized pediatric patients aged } \\
<12 \text { years weighing at least } 3.5 \mathrm{~kg}\end{array}$ \\
\hline 08-May-20 & Fresenius Kani Propoven $2 \%$ & $\begin{array}{l}\text { To maintain sedation via continuous infusion in patients } \\
\text { aged }>16 \text { with suspected or confirmed COVID-19 who } \\
\text { require mechanical ventilation in an ICU setting }\end{array}$ \\
\hline 13-Aug-20 & $\begin{array}{l}\text { REGIOCIT replacement solution that contains citrate for } \\
\text { RCA of the extracorporeal circuit }\end{array}$ & $\begin{array}{l}\text { To be used as a replacement solution only in adult patients } \\
\text { treated with CRRT, and for whom regional citrate antico- } \\
\text { agulation is appropriate, in a critical care setting }\end{array}$ \\
\hline 23-Aug-20 & COVID-19 convalescent plasma & For the treatment of hospitalized patients with COVID-19 \\
\hline 09-Nov-20 & Bamlanivimab & $\begin{array}{l}\text { For the treatment of mild-to-moderate COVID-19 in adult } \\
\text { and pediatric patients with positive results of direct } \\
\text { SARS-CoV-2 viral testing who are aged } \geq 12 \text { years } \\
\text { weighing at least } 40 \mathrm{~kg} \text { (about } 88 \text { pounds), and who are } \\
\text { at high risk for progressing to severe COVID-19 and/or } \\
\text { hospitalization }\end{array}$ \\
\hline 19-Nov-20 & $\begin{array}{l}\text { Baricitinib (Olumiant) in combination with remdesivir } \\
\text { (Veklury) }\end{array}$ & $\begin{array}{l}\text { For the treatment of suspected or laboratory-confirmed } \\
\text { COVID-19 in hospitalized adults and pediatric patients } \\
\text { aged } \geq 2 \text { years requiring supplemental oxygen, invasive } \\
\text { mechanical ventilation, or ECMO }\end{array}$ \\
\hline 21-Nov-20 & Casirivimab and imdevimab & $\begin{array}{l}\text { To be administered together for the treatment of mild-to- } \\
\text { moderate COVID- } 19 \text { in adults and pediatric patients } \\
\text { (aged } \geq 12 \text { years weighing at least } 40 \mathrm{~kg} \text { ) with positive } \\
\text { results of direct SARS-CoV- } 2 \text { viral testing, and who are } \\
\text { at high risk for progressing to severe COVID-19 and/or } \\
\text { hospitalization }\end{array}$ \\
\hline $09-F e b-21$ & Bamlanivimab and estesevimab & $\begin{array}{l}\text { For the treatment of mild-to-moderate COVID-19 in adult } \\
\text { and pediatric patients with positive results of direct } \\
\text { SARS-CoV-2 viral testing who are aged } \geq 12 \text { years } \\
\text { weighing at least } 40 \mathrm{~kg} \text { (about } 88 \text { pounds), and who are } \\
\text { at high risk for progressing to severe COVID-19 and/or } \\
\text { hospitalization }\end{array}$ \\
\hline 12-Mar-21 & Propofol-Lipuro $1 \%$ & $\begin{array}{l}\text { To maintain sedation via continuous infusion in patients } \\
\text { greater than age } 16 \text { with suspected or confirmed COVID- } \\
19 \text { who require mechanical ventilation in an ICU setting }\end{array}$ \\
\hline
\end{tabular}

COVID-19 Coronavirus Disease 2019, CRRT continuous renal replacement therapy, ECMO extracorporeal membrane oxygenation, EUA Emergency Use Authorization, $I C U$ intensive care unit, $R C A$ regional citrate anticoagulation

products (not shown here) including diagnostics, personal protective equipment (PPE), and medical devices have been authorized to combat the Zika virus, H7N9 virus, MERS-CoV, and Ebola virus [4]. Collectively, these events mark the historical successes that prove the utility of EUAs during times of public health emergencies, supporting its value as a regulatory tool.

\section{The EUA and Drugs Repurposed for COVID-19 Infection}

\subsection{Repurposing Existing Drugs for COVID-19}

A drug developed for one therapeutic indication can sometimes be found beneficial in selected situations for 
a different disease or condition. In fact, the first effective antiviral drug was being developed for cancer when insightful thinking led researchers to explore its antiviral activity [9]. This led to the development of acyclovir, an antiviral medication commonly used to treat human herpes infection, creating a new era in antiviral research, and leading to a Nobel Prize for Gertrude Elion and two other pharmaceutical industry colleagues [10].

Existing drugs repurposed for COVID-19 infection have been reviewed by Farne et al. [11] and classified into (1) antivirals, (2) promotors of innate antiviral response and (3) immunomodulatory/anti-inflammatory drugs. Drugs within these categories have reasonable likelihood of potential benefit, but the dose, dosing regimen, and precautions were not established for treatment of COVID-19 infections. The pathway to rapidly bridge these hypotheses to patient benefit is not straightforward. Early in the pandemic, two drugs in particular were hypothesized to have therapeutic potential and were frequently discussed in the media. Hydroxychloroquine and remdesivir were supported by reasonable therapeutic hypothesis and were seen as an immediate option while awaiting the discovery and development of a vaccine. While many took comfort in the fact that the drugs had a defined therapeutic window for the conditions they were originally developed to treat, we came to appreciate the intricacies of therapeutics in the often-overlooked efforts that go into defining a clear indication for the drug, its dose and dosing regimen, its safety and needed precautions and its contraindications-all the basic elements of a drug product label (i.e., package insert).

The authority to use unapproved drugs for COVID-19 came to light as the pandemic was unfolding. On February 4, 2020, the U.S Department of Health and Human Services (HSS) declared a public health emergency that supported an EUA. This allowed the FDA to approve unapproved medical product(s) to be used in an emergency to diagnose, treat, or prevent COVID-19 infection, a life-threatening disease.

\subsection{Hydroxychloroquine}

On March 28, 2020, the FDA issued an EUA for oral formulations of chloroquine phosphate and hydroxychloroquine sulfate [12]. Hydroxychloroquine, despite demonstrating antiviral effects in laboratory models [13], ultimately did not show an acceptable benefit-risk relationship for the use to treat COVID-19 infection in humans [14]. As clinical trial data emerged, the agency concluded the drug may not be effective for COVID-19 infection and that any potential benefit did not outweigh its known and potential side effects and the EUA was revoked on June 15, 2020 [15] (Table 3). Chloroquine's EUA did not last long. In addition to chloroquine phosphate and hydroxychloroquine sulfate, there were a number of other therapies and diagnostics that had their EUA revoked during the COVID-19 pandemic (Table 4).

Hydroxychloroquine's failure to show meaningful benefit became more critical when serious safety issues emerged. The FDA announced reports of serious arrythmias in patients with COVID-19 treated with hydroxychloroquine or chloroquine, often in combination with azithromycin and other QT prolonging medicines [16]. The FDA also noted their concern for public health as they observed increase outpatient prescriptions, possibly indicating increased requests for prescriptions to physicians by patients. The public was able to witness firsthand the two ends of a therapeutic index (benefit and risk) and the importance of each in therapeutic decisions.

The hope of repurposing hydroxychloroquine had faded despite misguided enthusiasm by some influencers including country presidents and even a physician who used sermons as a minister to foster misinformation [17].

\subsection{Remdesivir}

The FDA issued an EUA for remdesivir in hospitalized patients with severe disease from COVID-19 infection on May 1, 2020 [18] (Tables 2, 3). Use for the treatment of suspected or laboratory-confirmed COVID-19 in adults and children hospitalized with severe disease was expanded on August 28, 2020 [19], and was FDA approved on October 22, 2020 [20]. Although remdesivir was being developed primarily against Ebola, like hydroxychloroquine, it showed an effect against coronaviruses in laboratory models [21, 22]. A clinical study demonstrated that remdesivir use was not associated with an overall difference in time to clinical improvement. In patients with symptoms for 10 days or less, faster time to clinical improvement, compared to placebo, was observed but the difference was not statistically significant [23].

In addition to conducting the trial noted above, the remdesivir manufacturer began accepting physician requests for compassionate use. With safety data for some 500 patients in the Ebola program [24, 25], a reasonable hypothesis for benefit, and no other therapy available, a compassionate use program was initiated. The investigators were able to observe clinical improvement in $68 \%$ of patients and nobody experienced side effects [26]. Compassionate use was followed by reporting of the ACTT-1 Trial where remdesivir demonstrated superiority to placebo based on a shortened time to recovery in hospitalized adults with COVID-19 and evidence of lower respiratory tract infection [27]. These data led to the drug's authorization in the USA, EU, and UK. However, some uncertainty concerning the drug's ultimate utility arose from the WHO 12,000 Patient Solidarity Trial [28], where no effect on survival was observed. 
Table 3 Repurposing of drugs for the treatment of COVID-19 [11]

\begin{tabular}{|c|c|}
\hline & Description \\
\hline \multicolumn{2}{|l|}{ Antivirals } \\
\hline Remdesivir & $\begin{array}{l}\text { Developed to treat Ebola; antiviral activity against respiratory infections including SARS- } \\
\text { CoV-2 } \\
\text { Acts as an adenosine analog to interfere with viral RdRp and induce premature or delayed } \\
\text { RNA chain termination, while evading viral exoRNAase activity } \\
\text { Recent study demonstrated accelerated recovery in patients during early disease }\end{array}$ \\
\hline Favipiravir & $\begin{array}{l}\text { Developed to treat influenza in Japan; effective in vitro against RNA viruses including SARS- } \\
\text { CoV-2 } \\
\text { Acts as purine analog to disrupt RdRp } \\
\text { SARS-CoV-2 patients show shorter time to viral clearance and greater improvement in chest } \\
\text { radiographic appearances (open-label RCT) }\end{array}$ \\
\hline Lopinavir/ritonavir \pm ribavirin & $\begin{array}{l}\text { Developed to treat human HIV } \\
\text { LPV inhibit proteases that cleave viral polyprotein to lead to the formation of RdRp; RTV } \\
\text { inhibits cytochrome } 450 \text { to boost bioavailability of LPV } \\
\text { One open-label RCT using combination of LPV/RTV with IFN- } \beta \text { showed clinical improve- } \\
\text { ment in SARS-CoV- } 2 \text { patients }\end{array}$ \\
\hline Chloroquine and hydroxychloroquine & $\begin{array}{l}\text { Chloroquine developed to treat malaria; hydroxychloroquine analogs introduced due to } \\
\text { chloroquine-resistant strains of Plasmodium, treatment of autoimmune diseases including } \\
\text { lupus erythematosus and rheumatoid arthritis } \\
\text { Chloroquine and analogs undergo protonation and subsequent accumulation in lysosomes to } \\
\text { increase lysosomal pH, and interferes with viral trafficking; impairs autophagosome fusion } \\
\text { with lysosomes; inhibits glycosylation of angiotensin-converting enzyme } 2 \text { on cell surface } \\
\text { required for viral entry; interferes with TLR signaling and cyclic guanosine monophosphate } \\
\text { synthase to diminish downstream production of type-I IFNs and other cytokines } \\
\text { Majority of clinical studies reported no benefit; one study showed improvement in symptom } \\
\text { burden and reduction in C-reactive protein at } 28 \text { days at the cost of increased risks of } \\
\text { adverse events }\end{array}$ \\
\hline
\end{tabular}

Promoter of the innate antiviral response

Exogenous interferon therapy

Azithromycin

Exogenous anti-SARS-CoV-2 antibody

Immunomodulatory and anti-inflammatory drugs

Anti-IL-6 (tocilizumab, siltuximab)
Used for the treatment of chronic hepatitis B and C

High-dose of type-I and -III IFN shown to be effective against SARS-CoV and MERS-CoV both in vitro and in vivo

Single pilot clinical trial in SARS revealed that addition of IFN- $\alpha$ to corticosteroids was associated with clinical improvement. Limitations: IFN- $\alpha$ group received higher doses of corticosteroids, small sample size, IFN $\alpha$ given at a median 8 days after symptom onset

Drug screen preprint demonstrated antiviral activity against SARS-CoV-2

A macrolide antibiotic that induces antiviral IFN; shown to double levels of antiviral type-I and type-III IFN released from virus-infected bronchial epithelial cells; possesses antiinflammatory properties

Azithromycin with oseltamivir showed clinical benefit in patients with influenza; MERS patients treated with macrolides found no improvement in 90-day mortality or viral clearance (only included critically ill, not treated with macrolide until admission to intensive care, subset did not receive azithromycin)

Transfer of antibodies from recovered patient; passive immunity; received interest during the Ebola epidemic

An RCT showed no benefit in the primary outcome of time to clinical improvement but signifcant reduction in patients with severe but non-life-threatening COVID-19

Serious adverse events were infrequent but not absent

Humanized monoclonal antibody acting to block IL-6

Approved treatment for cytokine release syndrome, rheumatoid arthritis, systemic juvenile idiopathic arthritis

Clinical studies show mixed results with tocilizumab, and siltuximab, individually 
Table 3 (continued)

Description

IL-1 receptor antagonist (anakinra)

Developed to treat rheumatoid arthritis

Binding of SARS-CoV-2 activates the inflammasome to mediate the cleavage of pro-IL-1 $\beta$ into biologically active, and mature IL-1 $\beta$; results in influx of inflammatory cells; lung inflammation and fibrosis

Anti-IL-1 therapy with the recombinant IL-1RA (IL-1 receptor antagonist) protein anakinra shown to reduce mortality in patients with sepsis-related hyperinflammation

Corticosteroids

Synthetic analogues of steroid hormones; primarily used to treat immune-mediated diseases

Systemic corticosteroids to suppress SARS-COV-2-induced lung inflammation to prevent and/or treat ARDS; risk of inhibiting immune responses and impair pathogen clearance

Twenty-eight-day mortality was reduced with dexamethasone; reduced mortality in patients on mechanical ventilation, treated with oxygen but worsened survival in mild cases not requiring oxygen

Treatments that were granted an EUA are given in italics

ARDS acute respiratory distress syndrome, COVID-19 Coronavirus Disease 2019, HIV immunodeficiency virus, IFN interferon, IL interleukin, $L P V$ Lopinavir, MERS Middle East respiratory syndrome, $R C T$ randomized control trial, $R d R p$ RNA-dependent RNA-polymerase, $R N A$ ribonucleic acid, RTV Ritonavir, TLR toll-like receptor

The lack of any alternative therapy at this phase of the pandemic reinforced the need to continue remdesivir clinical development and allow compassionate use in the interim. Ultimately, enough evidence became available for FDA NDA approval [29].

\subsection{Antibody Therapies and Convalescent Plasma}

Subsequent to the frequent public discussion on hydroxychloroquine and remdesivir, this was followed by EUAs for antibody therapy with convalescent plasma for the treatment of hospitalized patients with COVID-19 [30] (Tables 2, 3). This was proceeded by EUAs for antibody therapy with bamlanivimab [31] as well as casirivimab and imdevimab [32] co-administration (Table 2).

An important public health component is accurate and truthful communication of drug effects to the public in order to build trust in the regulatory processes. In the case of plasma administration, the FDA commissioner overstated the efficacy of therapy to the public, misinformation that was criticized by other health experts [33]. The commissioner's prompt admission that the data could have been better represented helped reinforce trust, an element that subsequently came to the forefront in optimizing vaccine roll out.

\section{The EUA and the Urgency for Vaccine Development and Deployment}

The most celebrated use of EUAs came in mid-December 2020, with approvals for the Pfizer-BioNTech vaccine [34] followed a week later by ModernaTX's application [35], with the first administration of both occurring days later.
Nearing the end of February 2021, the third EUA was issued for the Janssen's (Johnson \& Johnson [J\&J]) single-dose vaccine [36] (Table 1). Thus, within a year of declaring a global pandemic, three vaccines using two platforms (mRNA and viral vector-based) were authorized for emergency use in the USA.

Basic pharmacovigilance led to interrupted authorization for the Janssen's viral vector vaccine. On April 13, the FDA and the Centers for Disease Control and Prevention (CDC) recommended a pause on the use of J\&J's vaccine after 6 reported cases of blood clots following vaccination [37-39]. After several days of data evaluation, the authorization was reinstituted with a warning on the low-risk association of vaccine-induced thrombotic thrombocytopenia (VITT) with the vaccine [40]. During this pause period, physicians became alerted to the type of clotting and appropriate therapy.

AstraZeneca's viral vector vaccine was authorized in Europe and elsewhere in early 2021 but has not yet been granted an EUA by the FDA. Concerns about robustness of Phase 3 trial data are probably related to lagging US approval and the need for additional data [41].

During the early stages of the pandemic, the FDA has guided the pharmaceutical industry to facilitate the satisfaction of scientific and regulatory requirements for the development and licensure, and EUA issuance of COVID-19 vaccines $[42,43]$. Once vaccine manufacturers complete a primary efficacy endpoint analysis in Phase 3 clinical trials that achieved the pre-specified success criteria of efficacy, an EUA application can be submitted to the FDA for review [43]. The FDA reviews data independent from the sponsor and can utilize an advisory committee of expert scientists and physicians from the Vaccines and Related Biological 


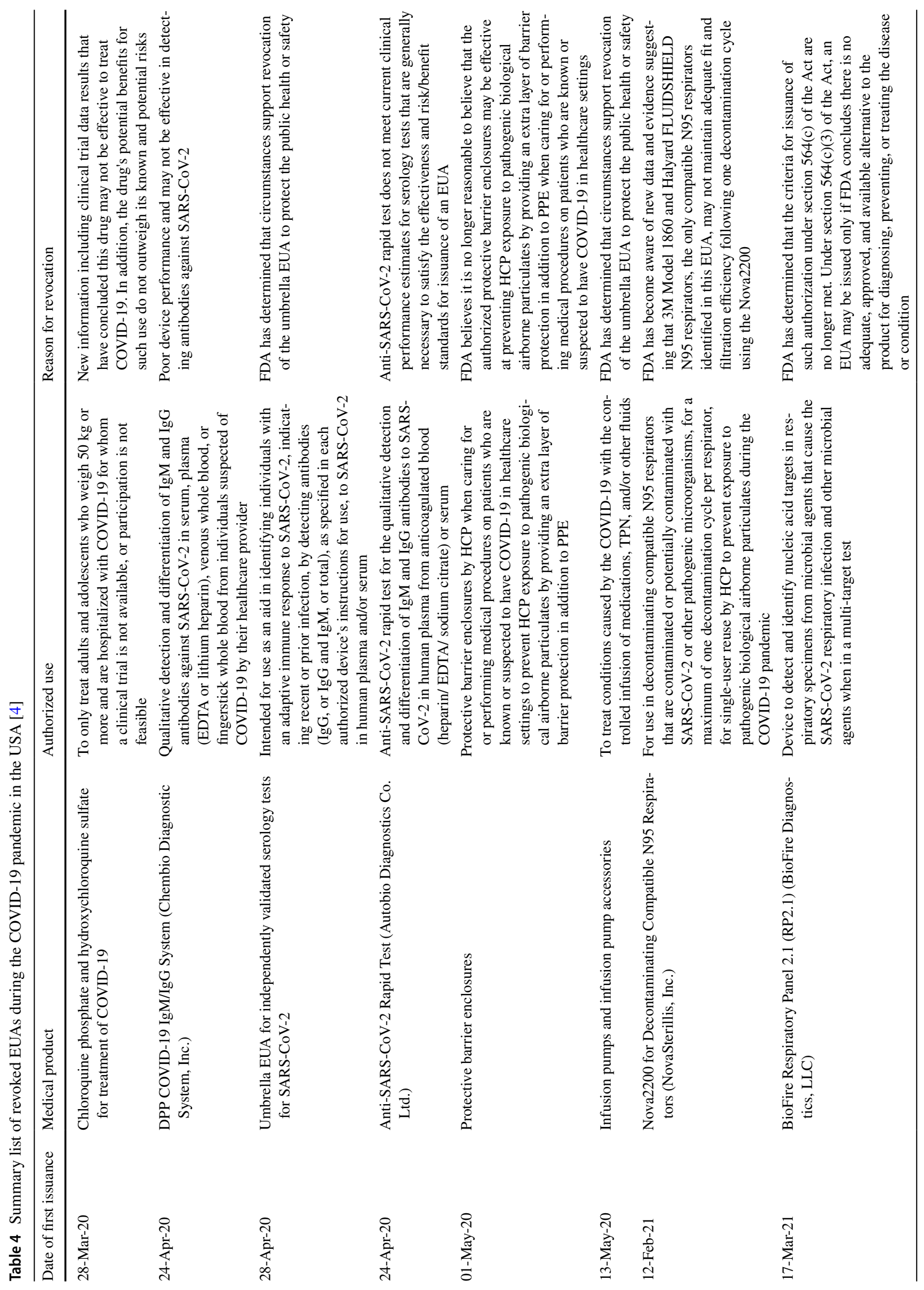




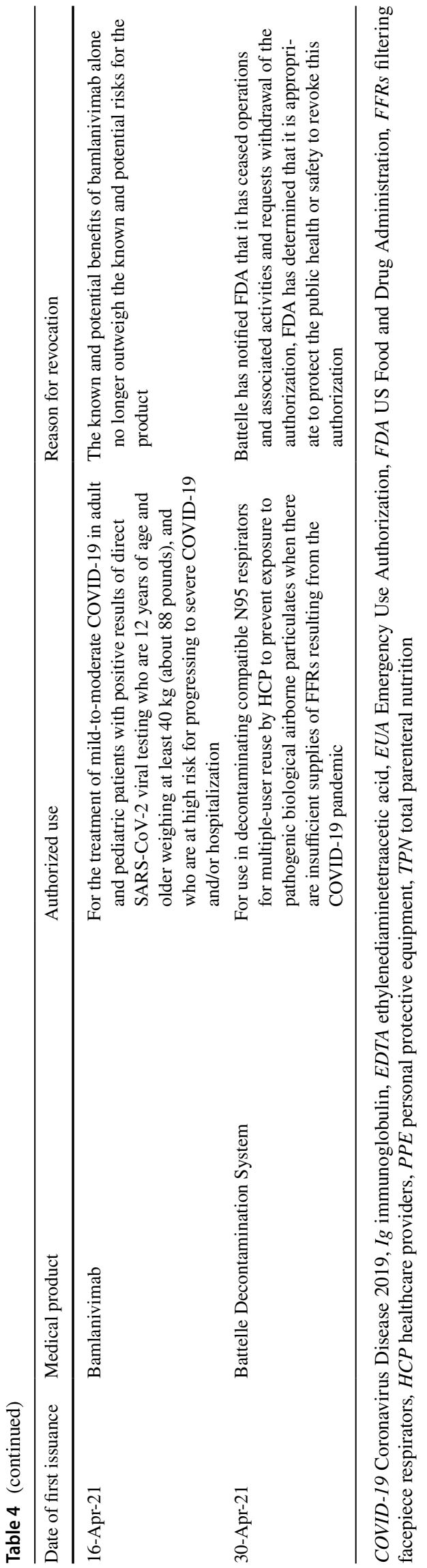

Products Advisory Committee (VRBPAC) [43]. This Committee deliberates on data in a public forum and votes on answers to questions provided by the FDA. While FDA is not bound by their recommendations, they usually follow them.

Robust pharmacovigilance follows EUA authorization, as demonstrated by the $\mathbf{J} \& \mathbf{J}$ case [37]. Full review of an NDA/ BLA will generally follow an EUA, which, in the case of vaccines, will include follow-up observations as defined by the Phase 3 protocol and evaluated in 'real world' studies of various designs. It is worthy to note that some COVID-19 vaccines are now progressing to full NDAs as their EUA will expire once the declared emergency is over. More recently, on August 23, 2021, the FDA approved Pfizer's COVID-19 vaccine for individuals 16 years or older [44].

\section{Perspective on EUA}

The approval of ddI for the treatment of AIDS was the first accelerated mechanism to bring lifesaving drugs to patients with no available alternatives [5]. Over a decade later, the origin of the EUA introduced the emergency use of the AVA to facilitate anthrax vaccine immunization of US military personnel with an increased risk of anthrax attacks [45]. These events along with the earlier pandemics, led to the use of EUAs, which have further supported and confirmed its utility during early public health emergencies.

In the COVID-19 pandemic, EUA vaccines were a remarkable accomplishment that was critical to mitigating the pandemic's negative effects. The temporary pause in one authorization reflected a system that was active and effective [37]. EUAs of therapeutics were also critical, as was the dynamic nature of their intention where we witnessed expansions of use, withdrawal of use, and progression to approved NDAs.

While our review focused on the USA, other jurisdictions used similar processes to expedite safe and effective authorization of vaccinations given the unmet needs posed by the COVID-19 pandemic. There are, however, noteworthy differences. In the USA, three vaccines are currently authorized for emergency use, which does not include the AstraZeneca product. This product was granted conditional marketing authorization by the European Medicines Agency (EMA), also a fast-track authorization procedure to speed up approval of treatments and vaccines during public health emergencies [46]. Similarly, a Marketing Authorization with Conditions was granted by Health Canada. Information on what additional data may have been requested by FDA and whether AstraZeneca will submit for an EUA, or full BLA, or no authorization or approval in the USA remains unclear [47]. 
Another distinction of the EUA review process in the USA is the independent advisory committee proceedings being open to the public [48]. While EMA and Health Canada strive for transparency in data access [49], the ability to witness the debates and rationale of opinions of independent experts is most transparent and informative, a model that should be considered by other authorities.

Finally, the process in the USA resulted in authorization based on the product label, which was informed by findings of robust clinical trial. In Canada, for example, vaccine procurement issues early on, forced authorities to make recommendations away from the product monograph. Specifically, the dosing intervals in the two-dose vaccines were allowed to be broadened [50]. This was followed by non-regulator recommendations allowing two-dose vaccine products to be mixed. Advisories then suggested limited use of the AstraZeneca vaccine [51]. Both of these practices were not studied in the pivotal trials driving the authorization, thus 'uncoupling' the data from these controlled studies, including long-term safety. While the ultimate benefit-risk of these debatable practices is unknown [52], it is noteworthy in the context of EUAs granted in the USA that ultimate dosing and administration did not stray from the data submitted by the sponsor and assessed by the FDA.

\section{Conclusion}

The EUA, originally designed to provide rapid antidotes for potential bioterrorism, acted as a critical regulatory pathway for vaccines and therapeutics throughout the COVID19 pandemic. Our experiences demonstrated the dynamic nature of the scientific review process where some products had their emergency use expanded, some withdrawn after evaluation of new data, and some moving on to full NDA approval. The EUA was a critical component in counteracting the pandemic through pharmaceutical medicine and proved a remarkable framework for the monumental drug development achievements. This experience will inform regulatory processes in future pandemics and public health crises.

\section{Declarations}

Funding No funding was received.

Conflict of interest We declare we have no conflicts of interest.

Availability of data and material Not applicable.

Code availability Not applicable.
Author contributions TW: conception of work, manuscript writing, responsible author. AT: writing of manuscript. TW and AT have read and approved the final paper and agree to be accountable for the work.

Ethics approval Not applicable.

Consent to participate Not applicable.

Consent for publication Not applicable.

\section{References}

1. Project BioShield Act of 2004, S 15, 108th Congress, (2004). https://www.congress.gov/bill/108th-congress/senate-bill/15. Accessed 14 May 2021.

2. U.S Food \& Drug Administration. MCM Emergency Use Authorities. U.S Food \& Drug Administration; 2021. https://www.fda. gov/emergency-preparedness-and-response/mcm-legal-regul atory-and-policy-framework/mcm-emergency-use-authorities. Accessed 14 May 2021.

3. U.S Food \& Drug Administration. Guidance Document: Emergency Use Authorization of Medical Products and Related Authorities. U.S Food \& Drug Administration; 2017. https://www. fda.gov/media/97321/download. Accessed 21 July 2021.

4. U.S Food \& Drug Administration. Emergency Use Authorization-Archived Information. U.S Food \& Drug Administration; 2021. https://www.fda.gov/emergency-preparedness-and-respo $\mathrm{nse} / \mathrm{mcm}$-legal-regulatory-and-policy-framework/emergencyuse-authorization-archived-information. Accessed 14 May 2021.

5. Expanding Access to Investigational Therapies for HIV Infection and AIDS. National Academies Press; 1991. p. 1778. https://doi. org/10.17226/1778

6. U.S Food \& Drug Administration. CFR - Code of Federal Regulations Title 21: Sec. 314.510 Approval based on surrogate endpoint or an effect on clinical endpoint other than survival or irreversible morbidity. U.S Food \& Drug Administration; 2020. https://www. accessdata.fda.gov/scripts/cdrh/cfdocs/cfcfr/cfrsearch.cfm?fr= 314.510. Accessed 20 July 2021.

7. U.S Department of Health and Human Services, Food \& Drug Administration, Centre for Drug Evaluation and Research (CDER) $\&$ Centre for Biologics Evaluation and Research (CBER). Guidance for Industry: Expedited Programs for Serious ConditionsDrugs and Biologics. U.S Department of Health and Human Services; 2014. https://www.fda.gov/files/drugs/published/Exped ited-Programs-for-Serious-Conditions-Drugs-and-Biologics.pdf. Accessed 21 July 2021.

8. U.S Food \& Drug Administration. Emergency Use Authorization. U.S Food \& Drug Administration; 2021. https://www.fda.gov/ emergency-preparedness-and-response/mcm-legal-regulatoryand-policy-framework/emergency-use-authorization. Accessed 14 May 2021.

9. Adams P. Meet the woman who gave the world antiviral drugs. National Geographic. August 31, 2020. https://www.nationalge ographic.com/science/2020/08/gertrude-elion-antivirals-coron avirus-remdesivir/\#close. Accessed 14 May 2021.

10. The Nobel Prize in Physiology or Medicine 1988. The Nobel Prize. Updated May 14, 2021. https://www.nobelprize.org/prizes/ medicine/1988/summary/. Accessed 14 May 2021.

11. Farne H, Kumar K, Ritchie AI, Finney LJ, Johnston SL, Singanayagam A. Repurposing existing drugs for the treatment of COVID-19. Ann ATS. 2020;17(10):1186-94. https://doi.org/10. 1513/AnnalsATS.202005-566FR. 
12. U.S Food \& Drug Administration. Letter of authorization-chloroquine phosphate and hydroxychloroquine sulfate. U.S Food and Drug Administration; 2020. https://www.fda.gov/media/136534/ download. Accessed 14 May 2021.

13. Yao X, Ye F, Zhang M, et al. In vitro antiviral activity and projection of optimized dosing design of hydroxychloroquine for the treatment of Severe Acute Respiratory Syndrome Coronavirus 2 (SARS-CoV-2). Clin Infect Dis. 2020;71(15):732-9. https://doi.org/10.1093/cid/ciaa237.

14. Hernandez AV, Roman YM, Pasupuleti V, Barboza JJ, White CM. Update alert 2: hydroxychloroquine or chloroquine for the treatment or prophylaxis of COVID-19. Ann Intern Med. 2020;173(7):W128-9. https://doi.org/10.7326/L20-1054.

15. U.S Food \& Drug Administration. Letter revoking EUA for chloroquine phosphate and hydroxychloroquine sulfate. U.S Food \& Drug Administration; 2020. https://www.fda.gov/ media/138945/download. Accessed 14 May 2021.

16. U.S Food \& Drug Administration. FDA cautions against use of hydroxychloroquine or chloroquine for COVID-19 outside the hospital setting or a clinical trial due to risk of heart rhythm problems. U.S Food \& Drug Administration; 2020. U.S Food \& Drug Administration. https://www.fda.gov/drugs/drug-safetyand-availability/fda-cautions-against-use-hydroxychloroquineor-chloroquine-covid-19-outside-hospital-setting-or. Accessed 14 May 2021.

17. Duong D. Why are we still talking about hydroxychloroquine? The anti-malaria drug has lost its allure as studies repeatedly show it doesn't treat COVID-19. Healthing.ca. 2020. https:// www.healthing.ca/diseases-and-conditions/coronavirus/weshould-stop-talking-about-hydroxychloroquine. Accessed 14 May 2021.

18. U.S Food \& Drug Administration. Coronavirus (COVID-19) Update: FDA issues emergency use authorization for potential COVID-19 treatment. U.S Food \& Drug Administration; 2020. https://www.fda.gov/news-events/press-announcements/coron avirus-covid-19-update-fda-issues-emergency-use-authorizat ion-potential-covid-19-treatment. Accessed 14 May 2021.

19. U.S Food and Drug Administration. COVID-19 update: FDA broadens emergency use authorization for veklury (remdesivir) to include all hospitalized patients for treatment of COVID-19. U.S Food and Drug Administration; 2020. https://www.fda.gov/ news-events/press-announcements/covid-19-update-fda-broad ens-emergency-use-authorization-veklury-remdesivir-includeall-hospitalized. Accessed 14 May 2021.

20. U.S Food and Drug Administration. Veklury (remdesivir) EUA Letter of Approval. U.S Food and Drug Administration. 2020. https://www.fda.gov/media/137564/download.

21. Agostini ML, Andres EL, Sims AC, et al. Coronavirus susceptibility to the antiviral remdesivir (GS-5734) is mediated by the viral polymerase and the proofreading exoribonuclease. MBio. 2018;9(2):e00221-e318. https://doi.org/10.1128/mBio.00221-18.

22. Wang M, Cao R, Zhang L, et al. Remdesivir and chloroquine effectively inhibit the recently emerged novel coronavirus (2019nCoV) in vitro. Cell Res. 2020;30(3):269-71. https://doi.org/10. 1038/s41422-020-0282-0.

23. Wang Y, Zhang D, Du G, et al. Remdesivir in adults with severe COVID-19: a randomised, double-blind, placebo-controlled, multicentre trial. Lancet. 2020;395(10236):1569-78. https://doi.org/ 10.1016/S0140-6736(20)31022-9.

24. Mulangu S, Dodd LE, Davey RT, et al. A randomized, controlled trial of ebola virus disease therapeutics. N Engl J Med. 2019;381(24):2293-303. https://doi.org/10.1056/NEJMoa1910 993.

25. European Medicines Agency. Summary on compassionate use: Remdesivir Gilead. European Medicines Agency; 2020. https:// www.ema.europa.eu/en/documents/other/summary-compassion ate-use-remdesivir-gilead_en.pdf. Accessed 14 May 2021.

26. Grein J, Ohmagari N, Shin D, et al. Compassionate use of remdesivir for patients with severe Covid-19. N Engl J Med. 2020;382(24):2327-36. https://doi.org/10.1056/NEJMoa2007016.

27. Beigel JH, Tomashek KM, Dodd LE, et al. Remdesivir for the treatment of Covid-19-final report. N Engl J Med. 2020;383(19):1813-26. https://doi.org/10.1056/NEJMoa2007764.

28. Dyer O. Covid-19: remdesivir has little or no impact on survival, WHO trial shows. BMJ. 2020. https://doi.org/10.1136/bmj. $\mathrm{m} 4057$.

29. Rubin D, Chan-Tack K, Farley J, Sherwat A. FDA approval of remdesivir - a step in the right direction. N Engl J Med. 2020;383(27):2598-600. https://doi.org/10.1056/NEJMp2032369.

30. U.S Food \& Drug Administration. Convalescent Plasma EUA Letter of Authorization. U.S Food \& Drug Administration; 2021. https://www.fda.gov/media/141477/download. Accessed 14 May 2021.

31. U.S Food \& Drug Administration. COVID-19 Update. FDA authorizes monoclonal antibody for treatment of COVID-19. U.S Food \& Drug; 2020. https://www.fda.gov/news-events/pressannouncements/coronavirus-covid-19-update-fda-authorizesmonoclonal-antibody-treatment-covid-19. Accessed 14 May 2021.

32. U.S Food \& Drug Administration. COVID-19 Update. FDA authorizes monoclonal antibody for treatment of COVID-19. U.S Food \& Drug Administration; 2020. https://www.fda.gov/newsevents/press-announcements/coronavirus-covid-19-update-fdaauthorizes-monoclonal-antibodies-treatment-covid-19. Accessed 14 May 2021.

33. Fink S., Thomas S. FDA 'Grossly Misrepresented' blood plasma data, scientists say. New York Times. August 24, 2020. Updated January 6, 2021. https://www.nytimes.com/2020/08/24/health/ fda-blood-plasma.html. Accessed 14 May 2021.

34. U.S Food \& Drug Administration. Pfizer-BioNTech COVID-19 Vaccine EUA Letter of Authorization. U.S Food \& Drug Administration; 2021. https://www.fda.gov/media/144412/download. Accessed 14 May 2021.

35. U.S Food \& Drug Administration. Moderna COVID-19 Vaccine EUA Letter of Authorization. U.S Food \& Drug Administration; 2021. https://www.fda.gov/media/144636/download. Accessed 14 May 2021.

36. U.S Food \& Drug Administration. Janssen COVID-19 Vaccine EUA Letter of Authorization. U.S Food \& Drug Administration; 2021. https://www.fda.gov/media/146303/download. Accessed 14 May 2021.

37. U.S Food \& Drug Administration. Joint CDC and FDA Statement on Johnson \& Johnson COVID-19 Vaccine. U.S Food \& Drug Administration; 2021. https://www.fda.gov/news-events/pressannouncements/joint-cdc-and-fda-statement-johnson-johnsoncovid-19-vaccine. Accessed 14 May 2021.

38. Greinacher A, Thiele T, Warkentin TE, Weisser K, Kyrle PA, Eichinger S. Thrombotic thrombocytopenia after ChAdOx $1 \mathrm{nCov}-$ 19 vaccination. N Engl J Med. 2021. https://doi.org/10.1056/ NEJMoa2104840.

39. Schultz NH, Sørvoll IH, Michelsen AE, et al. Thrombosis and thrombocytopenia after ChAdOx $1 \mathrm{nCoV}-19$ vaccination. $\mathrm{N}$ Engl J Med. 2021. https://doi.org/10.1056/NEJMoa2104882.

40. U.S Food \& Drug Administration. FDA and CDC Lift Recommended Pause on Johnson \& Johnson (Janssen) COIVD-19 Vaccine Use Following Thorough Safety Review. U.S Food \& Drug Administration; 2021. https://www.fda.gov/news-events/pressannouncements/fda-and-cdc-lift-recommended-pause-johns on-johnson-janssen-covid-19-vaccine-use-following-thorough. Accessed 14 May 2021.

41. Robbins R., Mueller B. After admitting mistake, astrazeneca faces difficult questions about its vaccine. The New York Times. 
November 25, 2020. Updated March 17, 2021. https://www.nytim es.com/2020/11/25/business/coronavirus-vaccine-astrazenecaoxford.html. Accessed 14 May 2021.

42. U.S Food \& Drug Administration, Center for Biologics Evaluation and Research. Development and licensure of vaccine to prevent COVID-19. Guidance for Industry. U.S Food \& Drug Administration, 2020. https://www.fda.gov/media/139638/download. Accessed 14 May 2021.

43. U.S Food \& Drug Administration, Centre for Biologics Evaluation and Research. Emergency use authorization for vaccines to prevent COVID-19. Guidance for Industry. U.S Food \& Drug Administration; 2021. https://www.fda.gov/media/142749/downl oad. Accessed 14 May 2021.

44. US Food \& Drug Administration. FDA Approves First COVID-19 Vaccine. Approval Signifies Key Achievement for Public Health. US Food and Drug Administration; 2021. https://www.fda.gov/ news-events/press-announcements/fda-approves-first-covid-19vaccine. Accessed 24 Aug 2021.

45. Nightingale SL, Prasher JM, Simonson S. Emergency use authorization (EUA) to enable use of needed products in civilian and military emergencies, United States. Emerg Infect Dis. 2007;13(7):1046. https://doi.org/10.3201/eid1307.061188.

46. European Medicines Agency. EMA recommends COVID-19 Vaccine AstraZeneca for authorization in the EU. Emergency Medicines Agency; 2021. https://www.ema.europa.eu/en/news/ ema-recommends-covid-19-vaccine-astrazeneca-authorisation-eu. Accessed 29 July 2021.

47. Rosenbaum L. Other countries have authorized astrazeneca's Covid-19 vaccine-why hasn't the U.S.? Forbes. February 19, 2021. https://www.forbes.com/sites/leahrosenbaum/2021/02/ 19/the-uk-the-eu-and-the-who-have-all-authorized-astrazenec as-covid-19-vaccine-- why-hasnt-the-us/?sh=af2e $5 \mathrm{f} 2350 \mathrm{e} 9$. Accessed 29 July 2021.

48. US Food and Drug Administration. Vaccines and Related Biological Products Advisory Committee. US Food and Drug Administration; 2019. https://www.fda.gov/advisory-committees/ blood-vaccines-and-other-biologics/vaccines-and-related-biolo gical-products-advisory-committee. Accessed 29 July 2021.

49. European Medicines Agency. EMA and Health Canada publish clinical data used to support their authorisations of the Moderna COVID-19 vaccine. Emergency Medicines Agency; 2021. https:// www.ema.europa.eu/en/news/ema-health-canada-publish-clinicaldata-used-support-their-authorisations-moderna-covid-19-vacci ne. Accessed 29 July 2021.

50. National Advisory Committee on Immunization (NACI). NACI rapid response: Extended dose intervals for COVID-19 vaccines to optimize early vaccine rollout and population protection in Canada. National Advisory Committee on Immunization (NACI); 2021. https://www.canada.ca/en/public-health/services/immun ization/national-advisory-committee-on-immunization-naci/rapidresponse-extended-dose-intervals-covid-19-vaccines-early-rollo ut-population-protection.html. Accessed 29 July 2021.

51. National Advisory Committee on Immunization (NACI) rapid response: interchangeability of authorized COVID-19 vaccines. National Advisory Committee on Immunization (NACI). https:// www.canada.ca/en/public-health/services/immunization/natio nal-advisory-committee-on-immunization-naci/recommenda tions-use-covid-19-vaccines/rapid-response-interchangeability. html. Accessed 29 July 2021.

52. Kadire SR, Wachter RM, Lurie NL. Delayed second dose versus standard regimen for Covid-19 vaccination. N Engl J Med. 2021;384:e28. https://doi.org/10.1056/NEJMclde2101987?artic leTools $=$ true.

53. Weiland N, Mandavilli A, LaFraniere S. F.D.A set to authorize pfizer vaccine for adolescents by early next week. The New York Times. May 3, 2021. Updated May 13, 2021 https://www.nytimes. com/2021/05/03/us/politics/coronavirus-vaccine-teenagers.html? referringSource=articleShare. Accessed 14 May 2021.

54. Anthes E. Pfizer and BioNTech apply for full U.S Approval for their Covid vaccine. The New York Times. May 7, 2021. https:// www.nytimes.com/2021/05/07/world/pfizer-vaccine.html?refer ringSource $=$ articleShare. Accessed 14 May 2021. 